\title{
Predictors of Smoking Cessation and Relapse after Hospitalization for Acute Coronary Syndrome
}

\author{
Jodi Summers Holtrop, PhD, CHEs ${ }^{1}$ \\ Manfred Stommel, $\mathrm{PhD}^{2}$ \\ William Corser, PhD, RN ${ }^{2}$ \\ Margaret Holmes-Rovner, $\mathrm{PhD}^{3}$ \\ ${ }^{1}$ Department of Family Medicine, College of \\ Human Medicine, Michigan State University, East \\ Lansing, Michigan. \\ ${ }^{2}$ College of Nursing, Michigan State University, \\ East Lansing, Michigan. \\ ${ }^{3}$ Center for Ethics and Humanities in the Life \\ Sciences, College of Human Medicine, Michigan \\ State University, East Lansing, Michigan.
}

Special thanks to Dr. Azfar Siddiqi for database management, Chrystal Price for data entry, and Camille Proden for chart abstraction and study recruitment. Supported by Agency for Health Research and Quality (AHRQ) grant number R01 HS 10531 (to M.H.-R.).
BACKGROUND: A hospital admission for a serious cardiac event offers a unique opportunity for smoking cessation. Understanding the factors that predict and enhance cessation among smoking cardiac inpatients is important for hospital physicians and clinical staff.

STUDY OBJECTIVE: To determine factors that predict smoking cessation, relapse, or continued smoking among posthospitalized cardiac patients who were smoking at the time of admission.

SAMPLE: Patients hospitalized with acute coronary syndrome (ACS) were recruited from 5 hospitals in Michigan to participate in a study assessing hospital quality improvement plus at-home health behavior change counseling.

MEASUREMENTS: Patient interview data were collected shortly after discharge and 3 and 8 months later to describe patient demographics, clinical characteristics, tobacco use, and other behaviors. Multinomial logit regression was used to predict smoking cessation, relapse, and continued smoking.

RESULTS: Of patients smoking at hospitalization who completed both follow-up interviews, $56.8 \%(\mathrm{n}=111)$ were not smoking at 8 months. A significant predictor of successful cessation was higher household income (odds ratio $[\mathrm{OR}]=4.72$; $P=0.003$ ), while having other smokers in the household decreased the odds of cessation ( $\mathrm{OR}=0.20 ; P=0.001$ ). History of depression increased the odds of relapse $(\mathrm{OR}=6.38 ; P=0.002)$ and being a lighter smoker decreased the odds $(\mathrm{OR}=0.16 ; P=0.026)$.

CONCLUSIONS: Although approximately one-half of the smokers in this study reported successful cessation, interventions are still needed to assist all smokers to successfully quit smoking after an ACS hospitalization. Our data suggest targeting follow-up programs to include other family members and using specialized methods for heavy smokers. Journal of Hospital Medicine 2009;4:E3-E9. () 2009 Society of Hospital Medicine.

KEYWORDS: heart disease, hospital inpatients, smoking cessation.

T obacco use in the United States is the chief avoidable cause of death in the United States. ${ }^{1}$ The health benefits of smoking cessation are widely known, including reductions in the risk for lung cancer, chronic obstructive pulmonary disease, and heart disease. ${ }^{2,3}$ Particularly for patients with symptomatic coronary artery disease, smoking cessation reduces the risk of mortality by $30 \%$ to $50 \%$.

Being hospitalized for a major cardiac event spurs many smokers to stop smoking. Acute and chronic health events are associated with a much lower likelihood of continued smoking, both immediately and over time. Cessation rates among smokers hospitalized for a cardiac condition, such as acute coronary syndrome (ACS), range from $31 \%$ without intervention to $60 \%$ with 
sustained intervention posthospitalization, at 1year follow-up. ${ }^{6-10}$

Various studies have examined predictors of continued smoking among patients with heart disease. However, few studies have focused on prognostic factors in patients hospitalized for their heart condition, illustrating a gap in the literature. Factors found to affect smoking cessation rates have included: mood disorders, such as current or history of depression, ${ }^{6,11-13}$ a high level of stateanxiety, ${ }^{13}$ and hostility or tensions, ${ }^{12}$ severity of disease, such as history of previous cardiac event, ${ }^{6,9}$ history of smoking-related pulmonary disease ${ }^{6}{ }^{2}$ severity of the cardiac disease, ${ }^{6,12}$ having 1 or more risk factors for coronary artery disease other than smoking, ${ }^{14}$ or unstable angina; ${ }^{14}$ greater nicotine dependence or heavy smoking at index hospitalization; ;,9,14,15 and the presence of other smokers in the home/work environment. ${ }^{16}$

Data from a recently completed randomized controlled trial of a health behavior intervention within the context of hospital quality improvement provided the opportunity to study factors predictive of successfully quitting smoking in hospitalized cardiac patients. The description and results of that trial, called the Heart After Hospitalization Recovery Program (HARP), are reported elsewhere. ${ }^{17,18}$ In summary, the health behavior intervention program studied in the trial was not successful in improving the smoking cessation rates above the control group receiving only the hospital quality improvement (QI) approach. Results of the QI intervention, the ACS Guidelines Applied to Practice (GAP) program, showed gains in survival that appeared to be due to better adherence to guidelines, which included a patient contract for behavior change. ${ }^{19,20}$ Therefore, the purpose of this work is to describe all the preadmission smoking patients in the study, regardless of trial group assignment, and examine predictive factors for smoking cessation and relapse to smoking after their hospital discharge for ACS.

\section{PATIENTS AND METHODS}

The institutional review boards of the authors' university and each of the 5 participating hospitals approved the HARP study.

\section{Settings and Subjects}

Patients were recruited from 5 hospitals located in 2 adjacent counties in a Midwestern state. The 2 counties were similar: each had 1 major city surrounded by suburbs and outlying rural and farming areas, diverse populations with a minority population higher than the state average (20\% versus $14.5 \%$ ), a high unemployment rate (above $8 \%$ ), and an industrial/manufacturing economic base.

Patient eligibility criteria included: admission to 1 of 5 participating study hospitals, a documented serum troponin I level greater than the upper limits of normal observed in each hospital, and a working diagnosis of ACS. Exclusion criteria included: discharge to any nonhome setting, possession of any significant mental/cognitive impairments, lack of a home telephone, or non-English speaking. Trained nurse recruiters approached hospitalized patients, providing information on study participation and attempting to obtain consent. Recruitment occurred between January 14, 2002 and April 13, 2003. A mean number of $2.29 \pm$ standard deviation (SD) 1.82 contacts were made with patients having elevated troponin levels to determine their actual eligibility.

\section{Measures}

Interview data were collected from patients at the following time points: shortly after hospital discharge (baseline), and 3 and 8 months postdischarge. Survey telephone calls lasted approximately 30 to 40 minutes and were conducted by trained survey researchers at the university's Institute for Public Policy and Social Research. Surveyors were blinded to the group assignment of the participants they were interviewing.

At the baseline interview, conducted between 1 and 4 weeks after discharge from the hospital (mean $14.11 \pm 9.6$ days), patients answered questions of survey interviewers including demographic and background information, comorbid conditions (Charlson comorbidity index [CCI] method),${ }^{21}$ history of depression, current depressive symptoms (Center for Epidemiological Studies-Depression [CES-D] tool ${ }^{22}$, and tobacco use.

Smoking status at the time of hospitalization was established based on 2 sources of information: the medical record chart audits, and the baseline interview. The baseline interview asked "Have you ever smoked tobacco?" Respondents answering "yes" were asked: "Do you smoke every day, some days, or not at all?"; "How many cigarettes do you now smoke per day on average?"; 
and "On average, when you smoked in the past 30 days, how many cigarettes did you smoke?" Respondents who reported that they quit smoking were asked when they had quit. Comparing the time between the baseline interview and the original hospital admission, the research team could establish who quit by the time of the baseline interview, but had still been a smoker at the time of hospitalization. Therefore, this group of patients was considered smokers for the purpose of this study; defined as smoking at the time of hospitalization for this heart event. All other patients were treated as nonsmokers. Smoking status at hospitalization was then confirmed with the hospital medical record, which provided information on whether the patient was a current, ever, or never smoker, the years smoked, and the number of packs currently smoked per day.

In the subsequent 3-month and 8-month interviews, each patient's reported smoking status and frequency was reassessed through the items, "Have there been any changes in your tobacco use in the past 3 months?" and "During the last month, have you smoked everyday, some days, or not at all?" If the patient reported current smoking, then he/she was asked "On the average, when you smoked during the past 30 days, about how many cigarettes did you smoke a day?" If the patient reported quitting, he/she was asked "How long ago did you quit smoking?" Household smoking was assessed by the question "In the past 30 days, has anyone, besides yourself, smoked cigarettes, cigars, or pipes anywhere inside your home?"

\section{Data Analysis}

In addition to descriptive statistics characterizing the analysis sample, the analysis relies on multinomial logit regression models to predict who among the smoking ACS patients discharged would continue to smoke, would quit for the observation period, or would relapse. ${ }^{23,24}$ Multinomial logit regression represents an extension of the more familiar binary logistic regression ${ }^{25}$ involving comparisons of all possible pairs of outcomes. Specifically, instead of employing separate logistic regression models to compare permanent quitters to continuing smokers, relapsers to continuing smoker, and permanent quitters to relapsers, these comparisons are contrasts in the multinomial model.
Thus, in addition to obtaining adjusted odds ratio (OR)s that take account of the simultaneous influence of all predictors, this analysis produces overall goodness-of-fit indicators and multivariate significance tests, which test whether coefficients associated with a particular independent variable have a simultaneous effect on the outcome across all categories. For instance, a multinomial $P$-value of less than 0.05 for a subject's history of depression would indicate that such a history has a significant effect on whether or not subjects continue to smoke, quit for good, or relapse. The specific ORs and their associated significance levels then indicate if and to what degree prior depression affects each 2-way contrast (quitters versus smokers, relapsers versus smokers, quitters versus relapsers). The analysis was conducted using the mlogit procedure of the STATA, 9.0 software package. ${ }^{26}$

\section{RESULTS \\ Subjects}

Of 719 consenting patients, $166(23.1 \%)$ were initially assessed to be smokers based on their medical record documentation. Smoking status at hospitalization could not be verified and smoking status after hospitalization could not be determined for 15 patients who did not participate in any of the follow-up interviews, therefore they were excluded. An additional 15 patients were excluded because of the lack of a second followup interview, which would have allowed us to determine whether they quit smoking for at least 3 months or relapsed. Therefore, we include only the 136 cases with generally complete interview data in the current analysis. Table 1 depicts the demographic, medical, and smoking-related characteristics of these patients.

\section{Significant Predictors of Cessation and Relapse}

Of the 136 smokers who were interviewed at baseline and completed the follow-up surveys, 45 continued to smoke at baseline and at subsequent interviews in which they participated $(33.1 \%)$ were defined as continuing smokers. Sixty-five patients quit smoking (quitters) and remained nonsmokers for the time of observation-at least 1 more interview wave or an additional 3 months $(47.8 \%$ of respondents). Twenty-six of the 136 (19.1\%) were relapsers. They reported quitting smoking shortly after their hospitalization, but reported smoking again at either the 3-month or 8-month interview. Smoking again was defined as answering "every 
TABLE 1

Demographic and Clinical Characteristics of Smoking HARP Patients at Baseline Interview (Preintervention)

\begin{tabular}{|c|c|c|}
\hline Variable & Number or Mean \pm SD & Percentage \\
\hline Age (years) & $53.32 \pm 9.52$ & \\
\hline \multicolumn{3}{|l|}{ Gender } \\
\hline Male & 83 & 61 \\
\hline Female & 53 & 39 \\
\hline \multicolumn{3}{|l|}{ White/nonwhite race } \\
\hline White & 112 & 82.4 \\
\hline Nonwhite/multiracial/other & 24 & 17.6 \\
\hline \multicolumn{3}{|l|}{ Marital status } \\
\hline Married & 80 & 59.3 \\
\hline Divorced/separated/widowed & 56 & 40.7 \\
\hline \multicolumn{3}{|l|}{ Work for pay or profit } \\
\hline Yes & 71 & 52.2 \\
\hline No & 64 & 47.1 \\
\hline Missing & 1 & 0.7 \\
\hline \multicolumn{3}{|l|}{ Highest education } \\
\hline High-school diploma or less & 79 & 58.1 \\
\hline Some college or more & 57 & 41.9 \\
\hline \multicolumn{3}{|l|}{ Family income } \\
\hline Less than $\$ 15,000$ per year & 36 & 26.5 \\
\hline$\$ 15,000$ or more per year & 90 & 66.2 \\
\hline No information & 10 & 7.4 \\
\hline \multicolumn{3}{|l|}{ Ejection fraction (EF) } \\
\hline $\mathrm{EF} \leq 35 \%$ & 14 & 10.3 \\
\hline $\mathrm{EF}>35 \%$ & 110 & 80.9 \\
\hline Unmeasured & 12 & 8.8 \\
\hline Number of comorbid conditions & $1.79 \pm 1.81$ & \\
\hline Number of persons living in household & $2.63 \pm 1.41$ & \\
\hline \multicolumn{3}{|l|}{ Past diagnosis of depression } \\
\hline Yes & 40 & 29.4 \\
\hline No & 96 & 70.6 \\
\hline
\end{tabular}

day or some days" to the question "During the last month, have you smoked every day, some days, or not at all?").

Table 2 shows the cross-tabulations and Table 3 shows the result from the multinominal regression analysis identifying significant predictors of quitting and relapsing as compared to continued smoking, relapsing versus quitting. Initially, the model included patient age (continuous variable), sex, years of education, race/ethnicity (other versus Caucasian) and insurance status (Medicare, Medicaid, employer-based private insurance, other private insurance, no insurance) among the predictor variables, but they were eliminated from the model based on the nonsignificance of the likelihood ratio chi square test associated with each of them. In the final model, we retained only significant predictor variables, except for 1: membership in the study groups (intervention group
TABLE 2

Cross-Tabulations Comparing Smokers to Successful Quitters and Relapsers Among Post-Hospital Discharge Acute Coronary Syndrome Patients Who Smoked When They Entered the Hospital

\begin{tabular}{|c|c|c|c|c|}
\hline Independent Variables & $\begin{array}{l}\text { Smokers } \\
{[\mathrm{n}(\%)]^{*}}\end{array}$ & $\begin{array}{l}\text { Relapsers } \\
{[\mathrm{n}(\%)]^{\dagger}}\end{array}$ & $\begin{array}{l}\text { Quitters } \\
\text { [n (\%)] }\end{array}$ & P-Value ${ }^{\S}$ \\
\hline \multicolumn{5}{|l|}{ Household income } \\
\hline$<\$ 15,000$ & $21(58)$ & $6(17)$ & $9(25)$ & \\
\hline$\$ 15,000+$ & $22(24)$ & $19(21)$ & $59(54)$ & 0.003 \\
\hline \multicolumn{5}{|l|}{ Study group } \\
\hline QI only & $22(37)$ & $13(21)$ & $25(42)$ & \\
\hline QI-plus HARP (coached) & $14(27)$ & $10(20)$ & $27(53)$ & \\
\hline QI-plus HARP (not coached) & $9(36)$ & $3(12)$ & $13(52)$ & 0.644 \\
\hline \multicolumn{5}{|l|}{ History of depression } \\
\hline No & $30(31)$ & $12(13)$ & $54(56)$ & \\
\hline Yes & $14(36)$ & $14(36)$ & $11(28)$ & 0.002 \\
\hline \multicolumn{5}{|l|}{ Smokers in household } \\
\hline No & $19(23)$ & $11(14)$ & $51(63)$ & \\
\hline Yes & $26(47)$ & $15(27)$ & $14(25)$ & 0.000 \\
\hline \multicolumn{5}{|l|}{ Intensity of smoking } \\
\hline Moderate/heavy & $26(29)$ & $13(15)$ & $49(56)$ & \\
\hline Light & $19(40)$ & $13(27)$ & $16(33)$ & 0.034 \\
\hline \multicolumn{5}{|c|}{ NOTE: $\mathrm{n}=136$; likelihood ratio $\chi^{2}=55.08$; degrees of freedom $=14 ; P<0.0001$. } \\
\hline \multirow{4}{*}{\multicolumn{5}{|c|}{$\begin{array}{l}\text { * Smokers are defined as those who continued to smoke after the hospitalization. } \\
{ }^{\dagger} \text { Relapsers are defined as those who quit smoking after hospitalization but had begun smoking again } \\
\text { by either the 3-month or 8-month interview. } \\
\text { ॠ Successful quitters are defined as those who quit smoking and remained quit for the observation } \\
\text { period. }\end{array}$}} \\
\hline & & & & \\
\hline & & & & \\
\hline & & & & \\
\hline \multicolumn{5}{|c|}{${ }^{\$}$ Significance tests associated with multiple category predictors. } \\
\hline
\end{tabular}

with coaching, intervention group without coaching, control group). To ease interpretation, the table displays 3 columns of the adjusted ORs, comparing all 2-way comparisons of outcomes. The third column, comparing relapsers and quitters, is technically redundant, as its ORs represent the ratios of the other 2 columns, but the values may be of interest to readers. The multinomial $P$-values in the right-hand column confirm that, with the sole exception of study group membership, every remaining independent variable is a significant predictor of smoking status after hospital discharge.

As the data show, patients with higher household incomes have substantially higher odds of quitting than low-income patients $(\mathrm{OR}=4.72 ; P$ $=0.001)$; yet they also have greater odds of relapsing $(\mathrm{OR}=3.38 ; P=0.04)$. Patients with a history/past diagnosis of depression are not more likely to quit than those without a depression history; however, they have larger odds of relapsing back to smoking (ie, the OR for the comparison of relapsers versus smokers $(\mathrm{OR}=2.66 ; P=0.05)$ almost reaches the conventional significance level, while the OR for the contrast of relapsers versus 
TABLE 3

Multinomial Logistic Regression Comparing Smokers to Successful Quitters and Relapsers Among Post-Hospital Discharge Acute Coronary Syndrome Patients Who Smoked When They Entered the Hospital

\begin{tabular}{|c|c|c|c|c|}
\hline Independent Variables & 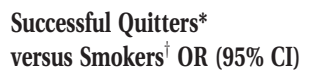 & $\begin{array}{l}\text { Relapsers }^{\dagger} \text { versus } \\
\text { Smokers }^{\dagger} \text { OR }(95 \% \mathrm{CI})\end{array}$ & $\begin{array}{l}\text { Relapsers }{ }^{*} \text { versus } \\
\text { Successful Quitters* 0R (95\% CI) }\end{array}$ & $\begin{array}{l}\text { Multinomial } \\
P \text { Value }^{\S}\end{array}$ \\
\hline \multicolumn{4}{|l|}{ Household income $(\$ 15,000)^{\|}$} & 0.007 \\
\hline$\$ 15,000+$ & $4.72(1.69-12.87)$ & $3.38(1.09-9.97)$ & $1.72(0.85-3.46)$ & 0.005 \\
\hline \multicolumn{4}{|l|}{ Study group (intervention) $\|$} & 0.56 \\
\hline QI-plus HARP (uncoached) & $0.86(0.24-3.05)$ & $0.46(0.10-2.65)$ & $0.53(0.26-1.09)$ & 0.65 \\
\hline QI only & $0.52(0.19-1.39)$ & $0.81(0.28-2.70)$ & $1.56(0.85-2.84)$ & 0.42 \\
\hline History of depression (yes) & $0.42(0.16-1.41)$ & $2.66(1.02-7.49)$ & $6.38(2.34-17.34)$ & 0.007 \\
\hline Smokers in household (yes) & $0.20(0.08-0.55)$ & $0.97(0.32-2.61)$ & $4.74(1.57-14.24)$ & 0.001 \\
\hline \multicolumn{5}{|c|}{ Intensity of smoking (moderate to heavy) $\|^{\|}$} \\
\hline Light & $0.20(0.04-0.99)$ & $1.29(0.44-3.56)$ & $0.16(0.05-0.57)$ & 0.08 \\
\hline \multicolumn{5}{|c|}{ NOTE: $\mathrm{n}=136$; likelihood ratio $\chi^{2}=55.08$; degrees of freedom $=14 ; P<0.0001$; Bolded items indicate significant relationships. } \\
\hline \multicolumn{5}{|c|}{ Abbreviations: CI, confidence interval; OR, adjusted odds ratio. } \\
\hline \multicolumn{5}{|c|}{ *Successful quitters are defined as those who quit smoking and remained quit for the observation period. } \\
\hline \multicolumn{5}{|c|}{${ }^{\dagger}$ Smokers are defined as those who continued to smoke after the hospitalization. } \\
\hline \multicolumn{5}{|c|}{ \$Relapsers are defined as those who quit smoking after hospitalization but had begun smoking again by either the 3-month or 8-month interview. } \\
\hline \multicolumn{5}{|c|}{${ }^{\S}$ Significance tests associated with multiple category predictors. } \\
\hline \multicolumn{5}{|c|}{${ }^{\|}$Reference category (comparison group in parentheses). } \\
\hline
\end{tabular}

quitters $(\mathrm{OR}=6.38 ; P=0.002)$ is significant and of substantial magnitude. By comparison, the presence of other smokers in a patient's household both lowers the odds of becoming a successful quitter $(\mathrm{OR}=0.20 ; P=0.001)$, and raises the odds of relapsing after initial quitting $(\mathrm{OR}=4.74$; $P=0.005$ ). While lighter smokers (defined as $<10$ cigarettes a day) before hospitalization do not appear to be more successful in quitting than heavier smokers (defined as $>20$ cigarettes a day) (OR $=1.29 ; P=0.62$ ), they are less likely to relapse to smoking if they quit $(\mathrm{OR}=0.16 ; P=0.03)$.

Specific results relating to the telephone counseling intervention are found elsewhere. ${ }^{17,18}$ However, we did include in Table 2 the specific results for the study groups to illustrate that the intervention program was not a factor predicting cessation. Analysis of the data using intention-to-treat (assuming all losses to follow-up were continuing smokers) resulted in similar findings at the 8month follow-up $\left(\chi^{2}=2.635\right.$; degrees of freedom $[\mathrm{df}]=2 ; P=0.268$ ).

\section{DISCUSSION}

The smoking cessation rate of $56.8 \%$ ( $\mathrm{n}=111$; only those with 8-month follow-up) in this study population at 8 months compares favorably with the range of $31 \%$ to $60 \%$ shown in earlier studies of cardiac populations. ${ }^{6-10,27}$ Assuming more con- servatively that the survey nonresponders were all smokers yields a $46.3 \%$ quit rate $(n=136$; all those with at least 1 follow-up), which is within the range reported in the literature.

The intervention program was not a factor predicting cessation. Most posthospital follow-up counseling is associated with increased smoking abstinence at follow-up. ${ }^{28,29}$ It is possible that the GAP in-hospital QI initiative in these hospitals contributed to improving the cessation of smokers in both trial arms, thereby negating the effect of the counseling-only option, although we did not specifically study the effect of the GAP intervention. It is also possible that we were underpowered to detect a statistically significant difference given our sample size of smokers.

Several characteristics were associated with successful smoking cessation in posthospitalized ACS patients. These included higher incomes, no other smokers in the household, and being a lighter smoker. We also found, however, that those with a history of depression, and heavier smokers also had higher rates of relapsing. As with previous research, our results support the evidence that heavier smokers have greater difficulty quitting smoking. ${ }^{6,9,14,15}$ Heavier smoking indicates a greater nicotine addiction. ${ }^{27}$ However, 1 study of smoking cessation of smokers at a tertiary referral, cardiothoracic hospital found that smokers with greater pack years (eg, number of years smoked at 
an equivalent of 1 pack per day), had a higher likelihood of abstinence at a 12-month followup. ${ }^{30}$ More intense efforts are likely needed to assist smokers with a more significant addiction. Perhaps studies are needed to better understand the physiological and genetic mechanisms of nicotine addiction and effective treatment options for this group.

Our results also demonstrate that those with a history of depression were more likely to relapse. Several researchers have demonstrated that in patients with a history of depression, return of depressive symptoms upon a cessation attempt may precipitate relapse. ${ }^{28,29}$ Current depressive symptoms, as measured by the CES-D, were not associated with decreased rates of quitting or relapsing. After controlling for history of depression, the CES-D score was no longer a predictor of quitting or relapsing in our data.

Similar to other studies, smokers in this study who reported having other smokers in the household had a more difficult time both quitting and remaining abstinent. ${ }^{16,31}$ A related controversy concerns the efficacy of including (smoking and nonsmoking) family members in interventions to sustain longer-term abstinence. Including family members has demonstrated efficacy in some research, ${ }^{32-34}$ although the optimal means of involving family members in smoking cessation interventions has not yet been identified. Severity of cardiac disease (as measured by ejection fraction) and the presence of comorbid conditions were not found to be associated with smoking continuation or cessation. We did not find in this sample of ACS patients that smoking cessation rates increased with age during the follow-up survey time points.

There are several limitations to our study. First, we did not biochemically validate selfreported smoking cessation rates. However, it is generally found that self-reports of cessation are accurate in research studies. ${ }^{35}$ Also participants may have incorrectly stated their quit rates due to recall bias. We were unable to fully capture use of smoking cessation pharmacotherapy (such as bupropion or nicotine replacement), which may have better explained success with cessation. Unfortunately, this is also not usually captured in the literature on studies of this nature. Last, since this study enrolled only cardiac patients in 2 similar community populations, these results may not be fully generalizable to other communities.
For smokers suffering from cardiac disease, there are few better ways to prevent a second heart event than quitting smoking. Judging from these results, there still remain a great number of hospitalized smokers who either choose to, or are unable to, successfully quit smoking, even after hospitalization for a serious cardiac event. Further research is needed to understand what individual motivating or household mechanisms may be best considered when encouraging this group of smokers to quit permanently.

Address for correspondence and reprint requests: Jodi Summers Holtrop, PhD, CHES, Department of Family Medicine, Michigan State University, B105 Clinical Center, East Lansing, Ml 48824; Telephone: (517) 884-0432; Fax: (517) 355-7700; E-mail: jodi.holtrop@hc.msu.edu

Received 22 October 2007; revision received 6 July 2008; accepted 13 July 2008.

\section{REFERENCES}

1. Mokdad AH, Marks JS, Stroup DF, Gerberding JL. Actual causes of death in the United States 2000. JAMA. 2004;291(10):1238-1245.

2. Goldstein MG, Niaura R. Methods to enhance smoking cessation after myocardial infarction. Med Clin North Am. 2000;84(1):63-80.

3. Edwards R. The problem of tobacco smoking. BMJ. 2004; 328:217-219.

4. Wilhelmsen L. Effects of cessation of smoking after myocardial infarction. J Cardiovasc Risk. 1998;5(3):173-176.

5. Wilson K, Gibson N, Willan A, Cook D. Effect of smoking cessation on mortality after myocardial infarction. Ann Intern Med. 2000;160:939-944.

6. Attebring MF, Hartford M, Hjalmarson A, Caidahl K, Karlsson T, Herlitz J. Smoking habits and predictors of continued smoking in patients with acute coronary syndromes. J Adv Nurs. 2004;46(6):614-623.

7. Hajek P, Taylor TZ, Mills P. Brief intervention during hospital admission to help patients to give up smoking after myocardial infarction and bypass surgery: randomised controlled trial. BMJ. 2002;324(7329):87-89.

8. Pederson LL, Wanklin JM, Lefcoe NM. The effects of counseling on smoking cessation among patients hospitalized with chronic obstructive pulmonary disease: a randomized clinical trial. Int J Addict. 1991;26(1):107-119.

9. Quist-Paulsen P, Gallefoss F. Randomised controlled trial of smoking cessation intervention after admission for coronary heart disease. BMJ. 2003;327(7426):1254-1257.

10. van Berkel TF, Boersma H, De Baquer D, Deckers JW, Wood D. Registration and management of smoking behaviour in patients with coronary heart disease. The EUROASPIRE Survey. Eur Heart J. 1999;20(22):1630-1637.

11. Mayou RA, Gill D, Thompson DR, et al. Depression and anxiety as predictors of outcome after myocardial infarction. Psychosom Med. 2000;62(2):212-219.

12. Brummett BH, Babyak MA, Mark DC, et al. Predictors of smoking cessation in patients with a diagnosis of coronary artery disease. J Cardiopulm Rehabil. 2002;22(3):143-147. 
13. Huijbrechts IP, Duivenvoorden HJ, Deckers JW, et al. Modification of smoking habits five months after myocardial infarction: relationship with personality characteristics. J Psychosom Res. 1996;40(4):369-378.

14. Hasdai D, Garratt KN, Grill DE, et al. Predictors of smoking cessation after percutaneous coronary revascularization. Mayo Clin Proc. 1998;73(3):205-209.

15. Ong KC, Cheong GN, Prabhakaran L, Earnest A. Predictors of success in smoking cessation among hospitalized patients. Respirology. 2005;10(1):63-69.

16. Chandola T, Head J, Bartley M. Socio-demographic predictors of quitting smoking: how important are household factors. Addiction. 2004;99(6):770-777.

17. Holtrop JS, Corser WD, Jones G, Brooks G, Holmes-Rovner M, Stommel M. Health behavior goals of cardiac patients after hospitalization. Am J Health Behav. 2006;30(4): 387-399.

18. Holmes-Rovner M, Stommel M, Corser WA, et al. Does outpatient telephone coaching add to hospital quality improvement following hospitalization for acute coronary syndrome? J Gen Intern Med. 2008;23(9):1464-1470.

19. Mehta R, Montoye C, Gallogly M, et al. Improving quality of care for acute myocardial infarction. The guidelines applied in practice (GAP) initiative. JAMA. 2002;287(10): 1269-1276.

20. Mehta R, Montoye C, Gallogly M, et al. Improving quality of care for acute myocardial infarction. JAMA. 2002; 287(10):1269-1276.

21. Charlson ME, Pompei P, Ales KL, MacKenzie CR. A new method of classifying prognostic comorbidity in longitudinal studies: development and validation. J Chronic Dis. 1987;40(5):373-383.

22. Devins G, Orme CM. Center for Epidemiologic Studies Depression Scale. In: Keyser DJ, Sweetland RC, eds. Test Critiques. Vol 2. Kansas City, MO: Test Corporation; 1985:144-160.

23. Agresti A. Categorical Data Analysis. New York, NY: Wiley \& Sons; 1990.
24. Long JS. Regression Models for Categorical and Limited Dependent Variables. Thousand Oaks, CA: Sage; 1997.

25. Hosmer D, Lemeshow S. Applied Logistic Regression. New York, NY: John Wiley \& Sons; 1989.

26. Stata Statistical Software: Release 9. College Station, TX: StataCorp LP; 2005.

27. van Berkel TF, Boersma H, De Baquer D, Deckers JW, Wood D. Registration and management of smoking behaviour in patients with coronary heart disease. The EUROASPIRE Survey. Eur Heart J. 1999;20(22):1630-1637.

28. Rigotti NA, Munafo MR, Murphy MF, Stead LF. Interventions for smoking cessation in hospitalized patients. Cochrane Database Syst Rev. 2003;(1):CD001837.

29. France EK, Glasgow RE, Marcus AC. Smoking cessation interventions among hospitalized patients: what have we learned. Prev Med. 2001;32(4):376-388.

30. Fung PR, Snape-Jenkinson SL, Godfrey MT, et al. Effectiveness of hospital-based smoking cessation. Chest. 2005; 128(1):216-223.

31. Miller CE, Ratner PA, Johnson JL. Reducing cardiovascular risk: identifying predictors of smoking relapse. Can J Cardiovasc Nurs. 2003;13(3):7-12.

32. Curry SJ, Hollis J, Bush T, et al. A randomized trial of a family-based smoking prevention intervention in managed care. Prev Med. 2003;37:617-626.

33. Park EW, Schultz JK, Tudiver F, Campbell T, Becker L. Enhancing partner support to improve smoking cessation. Cochrane Database Syst Rev. 2004;(3):CD002928.

34. Rohrbaugh MJ, Shoham V, Trost S, Muramoto M, Cate RM, Leischow S. Couple dynamics of change-resistant smoking: toward a family consultation model. Fam Process. 2001; 40:115-131.

35. Caraballo RS, Giovino GA, Pechacek TF, Mowery PD. Factors associated with discrepancies between self-reports on cigarette smoking and measured serum cotinine levels among persons aged 17 years or older: Third National Health and Nutrition Examination Survey, 1988-1994. Am J Epidemiol. 2001;153(8):807-814. 